\title{
Pansclerotic Morphea
}

National Cancer Institute

\section{Source}

National Cancer Institute. Pansclerotic Morphea. NCI Thesaurus. Code C116785.

A rare, aggressive form of morphea characterized by sclerosis of the dermis, fascia, and muscle over large parts of the body, resulting in contractures and immobility. 